\title{
Ciência, meio ambiente e qualidade de vida: uma proposta de pesquisa para uma universidade comprometida com sua comunidade
}

\author{
Science, environment and quality of life: \\ a research proposal for an university concerned \\ with its community development
}

Salvador dal Pozzo Trevizan 1

\begin{abstract}
Education and health are argued to be the starting points for social change toward a better quality of life. Social changes require quantity and quality of work which cannot be possible without increasing population's level of education, as knowledge, criticisms and professional capabilities, and without health, seen as physical and psychic pre-conditions for action. Science is seen as a discovering process and knowledge generation required to produce social change, but historically, quality of life has not been of great concern for science. This paper assumes that a great deal is given to the university in order to reverse that process. It is argued that an university that intends to improve quality of life must direct researching, teaching and extension programs for better services and goods alternatives for the poor, focusing social problems, on a multidisciplinary fashion.
\end{abstract}

Key words Science; Quality of Life; Interdisciplinary
Resumo O trabalho focaliza educação e saúde como pontos de partida para a mudança social em busca de melhoria na qualidade de vida. Mudanças requerem quantidade e qualidade de trabalho que não podem acontecer sem elevar o nível educacional, como conhecimento, capacidade critica e habilidades profissionais, e sem saúde, entendida como precondições físicas e psíquicas para a ação. A ciência é vista como processo de descoberta e geração de conhecimento necessários para as mudanças sociais, mas historicamente não tem sido usada para a melhoria da qualidade de vida. Papel importante cabe à universidade em reverter tal processo. Argumenta-se que a universidade que pretenda atuar na melhoria da qualidade de vida no meio ambiente em que se insere, necessariamente, terá que orientar suas linhas de pesquisa, ensino e extensão, na busca de alternativas de serviços e bens de qualidade aos menos afortunados, a partir de problemas sociais, num enfoque interdisciplinar, ao invés de abordagens segmentadas do conhecimento.

Palavras-chave Ciência; Qualidade de Vida; Interdisciplinaridade

1 Departamento

de Ciências Agrárias

e Ambientais, Universidade

Estadual de Santa Cruz,

Rodovia Ilhéus-Itabuna

Km 16, 45600-000

Ilhéus, BA.

salvador@jacaranda.

uescba.com.br 


\section{Introdução}

Mens sana in corpore sano, mente saudável em corpo saudável, eis o princípio implícito da discussão que envolve a trilogia em epígrafe. Ciência e qualidade de vida são dois pólos que se ligam ou se interceptam num contexto socioambiental, a depender de como atuam a educação e a saúde nesse contexto. A universidade tem o dever de colocar-se no centro dessa conexão. Essa é a tese que se pretende discutir.

Para clareza de discussão, consideramos necessário estabelecer alguns conceitos. Considera-se ciência um processo de descoberta e de construção do conhecimento, necessários para as mudanças sociais. A qualidade de vida, entendida como as condições de vida humana real (não apenas possível), existentes num determinado contexto ambiental e temporal, refere-se a um estado duradouro de condições humanas, fruto do trabalho. O efeito transformador do trabalho requer determinadas condições mentais (conhecimento e capacidade crítica ou poder de reflexão sobre o conhecimento adquirido), morais (capacidade de estabelecer critérios de valor ou juízos sobre o mundo conhecido), habilidades psicomotoras (saber fazer - capacidade de aplicação das condições mentais e morais existentes num contexto socioambiental) e vitais. A educação pode ser vista como o nível das condições mentais, morais e do saber fazer e, ao mesmo tempo, como processo de aquisição desse complexo de saberes. A saúde, entendida como as condições biológicas e psíquicas que caracterizam um determinado contexto ambiental e que condicionam a prática dos saberes e das habilidades para um processo de mudanças, determina um conjunto de fatores humanos que estabelecem uma precondição para a ação. ${ }^{1}$ Esta precondição também é um produto da educação num contexto socioambiental definido. As condições de saúde implicam o estado vital do ser humano e dependem de uma estrutura institucional voltada ao indivíduo e à coletividade. Como estado vital, o ser humano vive uma situação de maior ou menor risco, a depender da atenção institucional, derivada de políticas de saúde que, por sua vez, resultam de um processo social onde interesses e atores configuram uma realidade.

Níveis de qualidade de vida estão, pois, diretamente relacionados a níveis de educação e de saúde. Dadas as condições de saúde, os níveis existentes de educação da população e as facilidades da população em ascender níveis desejáveis dessas dimensões humanas, pode-se empreender um processo de transformação socioambiental desejada.

As condições morais permitem que, dentre as múltiplas possíveis ações que se apresentam a partir do conhecimento, da crítica e das habilidades, estabeleçamos uma escala de prioridades. A conformidade dos desejos, sonhos humanos ou aspirações às condições de vida humana real (não apenas possível), existentes num determinado meio ambiente, caracterizam a qualidade de vida.

Se o conhecimento, produto da ciência, é um componente necessário para mudanças, nem sempre esse produto predispõe para a mudança, assim como nem todo conhecimento supostamente apto para gerar mudança atinge tal fim. Para que assim aconteça, devese atuar com tal propósito no processo de produção do conhecimento e de sua socialização.

Em uma mesma sociedade, o baixo nível das condições mentais tende a coexistir com fortes barreiras para obtenção do conhecimento e com precárias condições de saúde que se juntam para inibir a ação transformadora. Mudanças nesse sentido podem ser obtidas através de lutas sociais e da atuação decisiva de instituições ligadas ao processo de formação das condições mentais, morais e do saber fazer do cidadão, particularmente a universidade. Muitas barreiras que impedem a ascensão na escalada do processo escolar e acesso aos serviços de qualidade estão associadas ao sistema social, podendo ser reduzidas através da luta da sociedade organizada.

À ciência cabe papel não menos importante, no comprometimento que faz para a solução dos problemas sociais e elevação da qualidade de vida no seu meio ambiente. Ciência não é mais vista como algo de conteúdos mágicos, desprovidos de interesses pessoais e/ou institucionais de quem a executa.

Educação e saúde constituem, pois, dois pilares centrais para se construir a qualidade de vida. São pré-requisitos para a conquista de novas condições mentais e habilidades necessárias ao processo de mudança. A educação, como ciência, representa as possibilidades de superação das barreiras que entravam o processo de busca dos saberes, em todos os campos do conhecimento; como nível de formação, representa uma quantidade e qualidade de saberes capazes de desencadear um processo de transformação. A saúde, por sua vez, 
estimula ou impede a práxis indispensável para efetivar o processo de mudança. Uma vez removidas as barreiras de acesso aos saberes e as que impedem o exercício dos saberes, teremos bases para iniciar um processo de melhoria da qualidade de vida humana.

É papel da investigação científica comprometida com o contexto socioambiental identificar as carências que impedem um processo de elevação da qualidade de vida e, em função delas, indicar ações. As carências podem ser definidas pela ausência absoluta (inexistência total), pela má qualidade dos bens e serviços oferecidos, ou pela ausência relativa (existem mas não são acessíveis - carência em função do sistema distributivo). Ações específicas necessitam adequar-se a cada uma destas formas de carência.

\section{Ciência e qualidade de vida: passado, presente e futuro}

Historicamente, o compromisso da ciência para com a qualidade de vida tem sido como a parábola bíblica do pobre que se alimenta com as sobras da mesa do rico. A ciência e a produção tecnológica têm se comprometido, na verdade, com as perspectivas de lucro e, por isso, têm estado a serviço do capital. Tal prática, contudo, esconde-se na ideologia de que o produto da ciência atende interesses sociais, isto é, contribui para a melhoria da qualidade de vida dos mais necessitados.

Dois procedimentos podem ser adotados para se avaliar essa problemática: 1) observar as fontes patrocinadoras da pesquisa ou a quem se destinam os recursos dessas fontes; e 2) verificar o produto final ao qual se destina a pesquisa.

Os recursos para $\mathrm{P} \& \mathrm{D}$, nos países desenvolvidos, segundo Guimarães et al. (1989), provêm, em primeiro lugar, de empresas (40\% a $60 \%$ ), vindo o Estado em segundo lugar (27\% a 50\%). Dessa contribuição, quase a totalidade vai para as indústrias orientadas à geração de "tecnologia de ponta". Se essa tecnologia traz alguma contribuição para melhorar a qualidade de vida humana nas regiões mais carentes, é algo, no mínimo, questionável. No mundo capitalista, os interesses das empresas estão no mercado, isto é, no capital. No caso específico dos Estados Unidos, França e Reino Unido, essa tecnologia tem fins militares. Reconhecer que os interesses da empresa e os objetivos militares, em uma sociedade capitalista, não estão orientados para fins sociais é reconhecer o óbvio.

Quanto à produção de alimentos, um estudo de Trevizan (1987) sobre a pesquisa agrícola na Universidade de Wisconsin ${ }^{2}$ ilustra o problema no setor agrícola americano. O trabalho mostra que até os primeiros anos do século XX, a pesquisa focalizava o interesse dos agricultores. A partir de 1906, a pesquisa foi direcionada para o uso industrial. Produtividade, seleção de produtos de melhor qualidade, maior diversidade de produtos, enfim, tudo o que interessava aos agricultores deixou de interessar à pesquisa. Mesmo assim, por volta dos anos 30, continuava-se argumentando que a ciência era utilizada para a melhoria da qualidade de vida, enquanto se evidenciava a ideologia de que a pesquisa era uma estratégia para se atingir as necessidades na nação. Em torno da década de 1960, o maior interesse e volume de recursos à pesquisa agrícola se concentravam em projetos com essa nova ideologia. O estudo conclui que a ideologia que governou a pesquisa no setor agrícola americano foi forjada pelas condições econômicas e políticas do país.

Nas décadas de 1950 e 1960 foi a vez da chamada Revolução Verde. Cleaver Jr. (1972) argumenta que era financiada e assessorada pela elite americana, e que foi não apenas um esforço para aumentar a produção, mas também para transformar as relações sociais e econômicas, integrando antigas áreas ou fazendeiros isolados ao mercado capitalista.

Referindo-se a instituições internacionais ligadas à produção agrícola como a Organização para Alimentos e Agricultura (FAO) e o Fundo Internacional para o Desenvolvimento Agrícola (IFAD), ambas ligadas às Nações Unidas, Talbot \& Moyer (1987) destacam que a primeira tem sido dominada por países industrializados do Ocidente e continua sendo uma instituição que promove apoio técnico aos projetos financiados pelos doadores. A segunda, por tratar-se de uma instituição com propósitos de financiar especialmente projetos destinados à produção de alimentos nos países em desenvolvimento, atingindo, assim, camponeses em condições de pobreza extrema, vive em permanente dificuldade para levantar fundos.

Uma reportagem de Mack (1998), divulgada pela New Scientist via Internet, denuncia o governo brasileiro por aprovar a introdução 
de um tipo de soja produzido através da engenharia genética e resistente ao herbicida Roundup, da multinacional americana Monsanto, enquanto milhões de brasileiros, nessa mesma ocasião, passavam fome por questões climáticas. O novo tipo de soja, diz a reportagem, vem reforçar os lucros dos grandes proprietários, quando a maioria dos agricultores brasileiros está trabalhando na produção de subsistência. Isso significa que o novo produto da Monsanto, aprovado oficialmente, não trará benefício algum para os milhões de brasileiros que passam fome. Ainda assim, diz o documento, os representantes das companhias defendem a tese de estar alimentando os milhões de famintos e conservando o meio ambiente.

$\mathrm{O}$ argumento de que a ciência e a tecnologia têm se formado, organizado e regulado por forças econômicas e políticas não é de hoje. A lucratividade é vista como a ideologia dominante da ciência. Os proprietários do grande capital são os que controlam os lucros da agricultura, sustenta Leontin (1982).

No campo da saúde, Fowler et al. (1988) argumentam que é muito simples melhorar as condições no hemisfério Sul, fazendo referência aos países pobres. Para eles, aumentar o acesso a medicamentos essenciais e serviços médicos ajuda muito; mas o principal é ter água e alimentos limpos, condições sanitárias e tratamento do lixo. Entretanto, enormes somas de dinheiro e grandes inteligências estão sendo dirigidas para a biotecnologia farmacêutica. É uma questão de custo de oportunidade, não de limpeza de água, de alimentos e habitação. Argumentam ainda que a área da pesquisa da biotecnologia que se apresenta com interesse para os pobres é a criação de vacinas. Mas a história sugere que vacinas tendem a ser mais acessíveis àqueles que menos necessitam delas. Segundo eles, de 14 vacinas produzidas por volta da década de 1990, doze delas são de maior interesse para uso no Norte.

Apesar dos resultados obtidos na área da genética, como o mapeamento do genoma humano e os corpos geneticamente modificados, significarem um avanço para a medicina, as regiões pobres não o usufruem pois sua infraestrutura para primeiros socorros está ainda, em parte, subdesenvolvida, e grande parte da população não tem acesso aos serviços médicos e aos medicamentos essenciais. Enquanto isso, os cientistas e as empresas do primeiro mundo retiram, sem controle e custo, exemplares das florestas remanescentes nos países pobres, para depois as devolverem, geneticamente modificadas ou mesmo sem chegar a tanto, a um preço inacessível à maioria da população dessas regiões.

Ao mesmo tempo em que há uma consciência generalizada de que o processo precisa ser revertido, não há perspectivas, a curto e médio prazo, de que isto venha ocorrer. A ideologia da globalização carrega implícita a necessidade de competição em um mercado de acesso irrestrito, onde vencem os mais fortes, e onde as regiões mais avançadas não estão dispostas a mudar seu padrão de vida e o modelo de crescimento. Ao lado disso, as regiões menos desenvolvidas caminham a reboque das primeiras, sempre definem, para as outras, os critérios de desenvolvimento e de qualidade de vida.

Mesmo que as perspectivas de mudança não sejam visíveis a médio alcance, cabe às comunidades, sem isolar-se do contexto global, preservar e desenvolver valores em nível regional. Identificar as carências básicas para implementar internamente as condições para um processo de melhoria da qualidade de vida é uma exigência que não implica esquecer o que acontece na esfera global, mas reclama uma posição crítica frente ao que é dominante e globalizante. Aqui se encontra o papel fundamental da universidade, instituição por excelência de produção e crítica do conhecimento. Maior ainda é o compromisso de uma universidade que se estrutura num contexto socioambiental carente das necessidades básicas para um padrão de vida de qualidade.

Pode ser futurista pensar em ciência e tecnologia do tipo transmutação genética, mas, ao mesmo, é tempo preocupante sentir-se constantemente ameaçado por problemas primários como malária, meningite, esquistossomose, analfabetismo, fome, desemprego. Tampouco é agradável, para quem quer que seja, conviver com o mau cheiro dos esgotos por onde se passa, ou com os lixões à vista desafiando nossa criatividade. Diante da presença constante desses desafios, não há como falar em qualidade de vida humana sem a iniciativa para superá-los.

\section{Qualidade de vida no contexto socioambiental do cacau}

No intuito de situar a qualidade de vida humana na região do cacau, em confronto com 
outras regiões, utilizam-se estatísticas definidas por município, no âmbito nacional, como o Índice de Condição de Sobrevivência (ICS) das crianças brasileiras, em uma publicação conjunta, de 1994, do Fundo das Nações Unidas para a Infância (Unicef) e a Fundação Instituto Brasileiro de Geografia e Estatística (IBGE) que, por si só, representa uma escala da qualidade de vida das populações municipais. Além daquele índice, consideram-se os percentuais de domicílios com abastecimento de água inadequado e taxas de mortalidade infantil e de analfabetismo.

Consideremos a qualidade de vida na região do cacau, em torno do eixo Ilhéus-Itabuna, a partir das condições gerais de sobrevivência das crianças. Quanto maior for o índice, piores são as condições. Assim, Itabuna e Ilhéus, com índices de 0,36 e 0,47 , respectivamente, apresentam as melhores condições da região, situando-se em uma posição intermediária $(0,30$ a 0,49$)$, conforme o documento da Unicef/IBGE (op. cit.). Já a maioria dos municípios apresenta condições classificadas como precárias, em nível nacional.

Tomando-se os percentuais de crianças de 0 a 6 anos em domicílios com abastecimento de água inadequado, mais de 50\% dos domicílios têm abastecimento inadequado. Em termos de Bahia, não é uma posição tão desfavorável, mas é deprimente se levarmos em conta que em outros estados o índice é de menos 10\%. Em uma publicação da prefeitura de Itabuna (1996), informa-se que 56\% dos domicílios urbanos no sul baiano não têm água fornecida por canalização interna.

As más condições sanitárias se refletem nas elevadas taxas de mortalidade infantil. A região do cacau situa-se na média do estado (em torno de 50 por mil), que está acima da média nacional (cerca de 40 por mil), mas representa o dobro das taxas verificadas nos estados do Sul. Se comparadas às taxas dos países desenvolvidos (menos de 10 por mil), verifica-se quanto se tem que caminhar para atingir padrões aceitos de qualidade de vida na região.

As perspectivas de melhoria das condições de vida podem ser vislumbradas a partir da capacidade crítica e do nível de escolaridade da população. Enquanto o espírito crítico representa o poder de discernir, o nível de escolaridade pressupõe determinado nível de informação, de conhecimento e habilidade profissional, qualidades indispensáveis para se iniciar um processo de mudança e de desenvol- vimento que culmina com a melhoria das condições de vida. Tais requisitos são condições de sustentabilidade para qualquer proposta de mudança, seja no mundo dos valores, seja no campo material. Desta forma, a educação, além de ser um componente básico do processo, é também um termômetro das condições para o desenvolvimento. Neste particular, a região do cacau, deixa a desejar. O baixo nível de escolaridade da população pode ser dimensionado pelo percentual de domicílios com chefe de família homem, com menos de um ano de escolaridade (geralmente em torno de $50 \%$ ). Este dado indica uma situação de analfabetismo das pessoas adultas. Apenas algumas exceções, em nível municipal, apresentam percentual de analfabetismo inferior àquele.

Os índices de analfabetismo de adultos indicam superposição de vários problemas educacionais no âmbito regional, como a entrada tardia no sistema escolar, elevadas taxas de repetência, abandono precoce do sistema escolar e um significativo percentual de pessoas que não têm acesso ao sistema escolar. A gravidade da situação regional destaca-se sobremaneira quando confrontada ao nível nacional e, mais ainda, ao nível internacional, com países do Primeiro Mundo.

Esta sucinta caracterização das condições de vida no âmbito regional fala por si sobre a necessidade de um processo de mudanças a ser desencadeado para a melhoria da qualidade de vida. $O$ fato da universidade brasileira terse colocado, historicamente, à margem do processo social não é novidade; mas é inconcebível que uma instituição de ensino superior em formação, situada num contexto de carências extremas, continue conivente com uma história de alienação.

\section{Educação e saúde, bases de uma linha de pesquisa em qualidade de vida}

Duas premissas estão implícitas neste tópico. Primeiro, a de que é possível desencadear um processo de mudança a partir das bases, isto é, não há necessidade de mudar o sistema na sua estrutura para desencadear um processo de mudança na estrutura do sistema. A negação desta premissa envolve descompromissarse e lavar as mãos, seja como pesquisador, professor ou outro profissional, como ser humano e como cidadão, frente à realidade a ser enfrentada. Segundo, a de que o núcleo de uma 
linha de pesquisa deve pautar-se em um problema concreto a ser resolvido e não em uma disciplina ou área do conhecimento. Esta segunda premissa reconhece a complexidade dos fenômenos e do contexto em que ocorrem, advogando a interdisciplinaridade e o abandono da especialidade como metodologia de investigação, tratamento e solução de problemas concretos. $\mathrm{O}$ abandono da especialidade, entretanto, não pode ser confundido com o abandono do especialista. É a presença deste, aberto para outras dimensões do problema, que permite a interdisciplinaridade.

É através da reconhecida necessidade da universidade comprometer-se com a melhoria das condições de vida no ambiente em que opera, trabalhando o processo de geração de conhecimento e crítica sobre as condições ambientais, com o propósito posterior ou simultâneo de ação para a mudança da mesma realidade, e agindo de forma integrada com as várias áreas do conhecimento, que se pode atuar numa linha de pesquisa direcionada para a qualidade de vida da população regional.

$\mathrm{Na}$ Universidade Estadual de Santa Cruz (UESC), centralizada no contexto socioambiental do cacau no sul baiano, esta preocupação começou a se manifestar formalmente em um seminário de pesquisa (outubro de 1998), com a temática Qualidade da Pesquisa e Qualidade de Vida. Embora essa linha de investigação ainda não esteja sendo induzida institucionalmente, diversas iniciativas espontâneas de projetos individuais vêm sendo conduzidas, com bases administrativas diversas. Projetos, por exemplo, de caracterização da estrutura alimentar da população de bairros pobres (Departamento de Economia), de farmacobotânica, de ofidismo (Departamento de Biologia), de caracterização da situação de saúde em bairros populares, na perspectiva de um novo modelo assistencial (Departamento de Saúde), de identificação e caracterização dos fenômenos de repetência e evasão escolar em diferentes sistemas de ensino (Departamento de Educação), todos convergem para um alvo comum: a qualidade de vida da população carente.

Essa convergência de interesses de investigação e ação reflete um compromisso não sistematizado da universidade na solução de problemas reais da sua comunidade. Tal convergência é, na verdade, o resultado do funcionamento não segmentado da realidade, de modo inverso à forma como, tradicionalmente, se tem estruturado a ciência e o processo de construção do conhecimento. Em algum momento da caminhada social para a construção do saber, a mão invisível da natureza faz com que o processo de segmentação do conhecimento traia a si mesmo, reconduzindo as preocupações individualizadas à solução de problemas coletivos.

À medida que amadurece o compromisso da universidade para a qualidade de vida, as iniciativas espontâneas serão induzidas de forma coletiva e sistemática, podendo gerar maiores benefícios para ambas as partes na relação comunidade-universidade.

A opção pela qualidade de vida envolve um compromisso maior com as condições sociais da maioria desassistida dos serviços que a sociedade oferece. Se vivemos em condições ambientais em que elevado percentual da população sofre as precárias condições de educação e saúde, bases do processo para o desenvolvimento, a sustentabilidade de qualquer outro projeto de desenvolvimento pode estar ameaçada. Além da preocupação com a qualidade de vida, o saber tornou-se mola mestra de todo o processo produtivo e, como afirmam Oliveira \& Moura Castro (1993), o sistema educacional pode comprometer qualquer proposta de competitividade e eficácia.

No campo da saúde, se elevados percentuais da população não têm acesso ao sistema de saúde, há que se investigar para criar modelos alternativos. Se forem precários os conhecimentos relacionados a problemas de saúde típicos de populações carentes, há que se investir nessa direção. Pesquisas sobre plantas medicinais, por exemplo, permitem a correção de maus usos e aumentam a possibilidade de acesso a medicamentos baratos. Costa et al. (1998) revelam que, para 79\% das pessoas pesquisadas, o preço das consultas e dos remédios interferem na decisão de tratar-se com plantas medicinais. Argolo et al. (1998) mostram que as investigações sobre ofidismo estão permitindo melhor caracterização da sintomatologia de envenenamentos provenientes do contato com animais peçonhentos próprios da região, além de um trabalho educativo no relacionamento com tais animais, resultados que atendem demandas provindas especialmente da população rural que é ainda significativa na região e dominantemente pobre. Trevizan \& Eloy (1997) indicam que a base alimentar do trabalhador da roça, na região do cacau, está na carne seca e farinha de mandioca, uma dieta rica em proteínas e calorias, mas 
sem alimentos reguladores e sem variedade que poderia se dar com produtos de fácil acesso aos trabalhadores do campo, mediante uma ação educativa.

Obviamente, a precondição dos resultados da pesquisa para a melhoria das condições de vida depende do acesso à informação. Cabe, assim, à universidade definir estratégias de socialização do conhecimento produzido. $\mathrm{O}$ acesso à informação, entretanto, está condicionado ao nível de escolaridade. Nesta área, pesquisas específicas que identifiquem os fatores que entravam o processo de escolarização, como analfabetismo, repetência, evasão precoce e má qualidade do ensino, e a sua situação geográfica, permitem desenvolver ações específicas e localizadas, de acordo com cada contexto. A falta de conhecimento específico pode inviabilizar medidas concretas. Neste particular, uma análise sobre escolas públicas e privadas no eixo Ilhéus-Itabuna revela que a elevada taxa de repetência escolar, caracterizada, em nível nacional por Oliveira \& Moura Castro (1993), como típico das séries iniciais, é nessa região um problema que atinge de forma mais acentuada todo início de uma nova etapa escolar: primeira e quinta séries do primeiro grau e primeira série do segundo grau,

\section{Notas}

1 Esta não é uma tentativa de discutir a teoria da ação.

2 A Universidade de Wisconsin disputa a liderança entre as universidades americanas que mais investem em pesquisa.

\section{Agradecimentos}

O autor agradece à professora Adélia Maria C. M. Pinheiro, por sua valiosa contribuição, através da leitura e comentários criteriosos, e aos revisores anônimos, por suas observações em favor da melhoria da qualidade do texto. conforme descrevem Trevizan \& Bittencourt (1998). Gonçalves e Santos (1998) mostram que a falta de clareza do processo pedagógico, por parte de professores, contribui para as elevadas taxas de reprovação nas séries iniciais. Enquanto isto, Assis \& Lima (1998) concluem que a entrada tardia no sistema escolar é fator relevante a considerar para se reduzirem os entraves da aprendizagem.

Educação e saúde: eis pois a base para um início de conversa sobre mudança e sustentabilidade do contexto socioambiental em que vivemos. Sem mente sã num corpo sadio não haverá condições para o conhecimento, a reflexão, a criatividade e a ação transformadora. Com eles estaremos definindo um perfil de mão-de-obra para o trabalho, um perfil humano para a criatividade e o empreendedorismo, e estaremos definindo as condições de sustentabilidade social, econômica e ambiental do nosso contexto. Estaremos, enfim, traçando um potencial com habilidades para corrigir as distorções e desacertos, antecipar-se aos problemas e atuar no aperfeiçoamento das condições ambientais, a fim de elevar a qualidade de vida populacional, através do acesso a melhores serviços e bens, compatíveis com os horizontes sonhados.

\section{Referências bibliográficas}

Argolo A et al. 1998. Distribuição geográfica das serpentes peçonhentas do sudeste da Bahia. p. 56. V Seminário de Pesquisa da UESC, Ilhéus, BA.

Assis R \& Lima RG 1998. Repetência: produto da defasagem entre série e idade. p. 32. V Seminário de Pesquisa da UESC, Ilhéus, BA.

Cleaver Jr. HM 1972. Contradictions of the Green Revolution. Monthly Review 2(June):81-111.

Costa L et al. 1998. Estudo etnobotânico de plantas medicinais nas cidades de Ilhéus e Itabuna. p. 76. V Seminário de Pesquisa da UESC, Ilhéus, BA.

Fowler C, Lachkovics E, Mooney P \& Shand H 1988. The laws of life; another development and the new biotechnologies. Development Dialogue: The Laws of Life 1-2:145-170. 
Fundo das Nações Unidas para a Infância \& Fundação Instituto Brasileiro de Geografia e Estatística 1994. Municípios Brasileiros: Crianças e suas Condições de Sobrevivência. Brasília. 247 pp.

Gonçalves A \& Santos R 1998. Reprovação e evasão: onde estão esses fantasmas? p. 33. V Seminário de Pesquisa da UESC, Ilhéus, BA.

Guimarães EA, Araújo JT \& Erber F 1989. Política científica e tecnológica: as experiências dos países de senvolvidos, pp. 19-32. In MRA Magalhães \& A Habert (orgs.). Política, Ciência e Tecnologia para a Década de 90. Editora Universidade de Brasília, Brasília.

Itabuna 1996. Prefeitura Municipal. Coordenadoria de Governo e Assuntos Estratégicos. Supervisão de Planejamento e Projetos. Itabuna em Números. 2a ed. Itabuna, BA. $159 \mathrm{pp}$.

Leontin R 1982. Agricultural research and the penetration of capital. Science for the People, 14(1):12-17.
Mack D 1998. Food for all. New Scientist. 31 de outubro. http://www.newscientist.com/nsplus/insight/ gmworld/gmfood/develop.html. 6 pp.

Oliveira JBA \& Moura Castro C 1993. Ensino Fundamental e Competitividade Empresarial. Instituto Herbert Levy, Brasília/São Paulo/Rio de Janeiro. 122 pp.

Talbot RB \& Moyer HW 1987. Who governs the Rome food agencies? Food Policy 12(4):349-364.

Trevizan SDP 1987. Freedom for making science. Departamento de Sociologia, Universidade de Wisconsin, Madison, EUA. 27 pp. (Trabalho de pesquisa sobre história da ciência, produzido no programa de doutorado. Não publicado).

Trevizan SDP \& Bittencourt L 1998. Fracasso escolar nas escolas públicas e privadas: semelhanças e diferenças. p. 31. V Seminário de Pesquisa da UESC, Ilhéus, BA. Trevizan SDP \& Eloy AL 1995. Nível alimentar da população rural na região cacaueira da Bahia. Boletim Técnico no 180. CEPLAC/CEPEC, Ilhéus. 17 pp. 